\title{
A História do Direito: Aspectos Conceituais
}

\author{
Eugênio Carlos Callioli \\ Advogado em São Paulo \\ Pós-graduando da FADUSP
}

\begin{abstract}
RESUMO: A evolução do conceito de história e os vários modos de conceber este conceito: processo de crescimento linear e irreversível; processo de reversão periódica, em forma de ciclos; e progresso irrepetível, resultante das experiências que os ciclos que se iniciam tomariam dos que fenecem. A história do Direito como parte da história geral. A distinção entre história externa e interna do Direito. O objeto da história do Direito. $\mathrm{O}$ conhecimento crítico das fontes como fundamento do método da história do Direito. $\mathrm{O}$ modo de exposição da história do Direito: cronológico e sistemático. As duas grandes vertentes do "historicismo".
\end{abstract}

\begin{abstract}
S: The evolution of the concept of history and the various means to conceive the concept. They are: process of linear and irreversible growth; process of periodical revisions, in the form of cycles, and not repeating progress, resultant from the experiences that the starting cycles gain from the preceding ones. The history of law as a part of world history. The critical knowledge of sources as the fundamental method of the history of law. The means of exposition of the history of law: chronological and systematical. The two great currents of "historicism".
\end{abstract}

\section{CONCEITO DE HISTÓRIA: ACEPÇÕES E ONTOLOGIA}

O problema com relação ao conceito de história é o relativo à dualidade de significados. Os fatos e seu. conhecimento ficam abarcados sob a mesma denominação. A complexidade do problema aparece ademais na multiforme evolução do conceito de história que o homem desenvolveu. Reduzindo estas variantes e suas posições mais simplistas, poderíamos estabelecer um esquema tríplice: os que concebem a história como um processo de crescimento linear, irreversível, para uma meta humana ou sobrenatural; os que a entendem como um reverter periódico, em forma de ciclos; os que integram ambas as posturas e defendem um progresso irrepetível, resultante das experiências que os ciclos que se iniciam tomariam dos que fenecem. A visão da história como processo linear 
com fim sobrenatural é própria do pensamento cristão; como secularização ou laicização do mesmo, surge a visão linear com fim intramundano, como ocorre no positivismo e no marxismo. A pura concepção cíclica corresponde à proposta grego-romana. A defesa de um processo com base cíclica é típica de uma grande variedade de escolas (com variantes substanciais) que vão desde N. Maquiavel (1469-1527) e G. Vico (1668-1744), até os grandes sistemas dos séculos XIX e XX (Hegel, Spengler, Toynbee). Há outras propostas para as quais não é fundamental a compreensão integral do acontecer humano. Incidem com maior intensidade sobre a estrutura imediata da ciência histórica: sobre seu objeto, sua metodologia, etc.

Não é o escopo destas linhas adentrar no estudo destas tendências. Basta, para nosso fim, fazer alguma consideração sobre o que poderíamos chamar a "Ontologia da história".

Por "histórico", como por "historicidade", pode designar-se ou o acontecido e conseqüentemente possível tema do historiador (plano semântico da 'existência') ou o que por essência exige que, em caso de existir, 'exista' em história. Em suma, ambas as concepções remetem à história.

Prescindindo-se da possível ampliação, por analogia, à natureza, a história reserva-se ao humano, e, dentro dele, ao suceder singular irreversível (não a processos psicológicos que se repetem) enquanto campo aberto a sempre mais amplas conexões, por mais que um estudo concreto tenha que recortá-la a um determinado marco (a história de tal indivíduo, grupo, nação, etc.). Delimitando, assim, a amplitude de história, investigaremos o que ela vem a ser.

Antes de tudo, é 'pretérito' (ou se futuro, devemos supor já passado), a julgar pela mais usual definição da historiografia como "estudo do passado", acepção que avalizam expressões como "passar à história", "ser já história", "ter mero valor histórico". Ainda que esta preteriedade não seja uma categoria de essência, mas de posição (C. Seignobos), possui sua objetividade, já que é irreversível, inegável, irreparável, e é preciso fazer-lhe justiça. Com referência à presente possibilidade de atuar, o pretérito faz-se "tardio", assim como o futuro "cedo", e o presente, o 'kairós' ou "tempo oportuno". Precisamente por estas propriedades mencionadàs, exerce o pretérito esta enigmática atração fascinante que o homem atual de cada época tenta vencer com vistas ao adiante, deixando monumentos e crônicas, e, ao de trás, evocando o passado. No entanto, é fácil advertir espontaneamente que nem tudo do passado é histórico, nem quanto mais passado mais histórico.

Se há, agora, com relação a nosso presente um passado, é porque antes, como agora mesmo, "passou" algo. Logo a história também é a 'fortiori' um passar, isto é, um advir do que era até então futuro e um deixar de ser do que era presente. A este aspecto alude a imagem que parece ser imprescindível à 
história (a do 'curso' do rio), assim como as denominaçōes tomadas do tempo ("crônicas", "anais", "décadas", "diários"). Assim a história é a cada momento a vanguarda do presente, se bem enquanto já "congelado" e abandonado. Agora, o passado exige sê-lo de alguém ou de algo, ainda que fosse este sujeito referencial indefinido que mencionamos como "o conjunto do ocorrido". Em todo o caso, só com uma comparação conseguimos explicar este aspecto da história: com o paradigma do poema - ou ao menos da proposição oral - cada um de cujos elementos não advém sem o desaparecimento do anterior e, no entanto, este não adquire sentido senão a partir da totalidade do que se vai seguir. Também a história (a universal e a de cada setor) propriamente só o é quando todos os seus elementos (acontecimentos) deixaram de ser. Obviamente, este passar cabe considerá-lo como destruidor ou como construtor (de impérios, religiões, obras de arte e técnica).

Apesar dos acasos, a história é também continuação. É deste prisma que tem sentido o matiz elogioso das expressões "personagem histórico", decisões e palavras "verdadeiramente históricas", "fazer história", e em função de tal suposição é que o historiador seleciona o digno de relato. Precisamente por isto pode definir-se história como o "passado que sobrevive" Se se acentua além de certo limite a continuidade, chega-se à consideração da história como 'recorrências' (repetição de acontecimentos) em virtude de certas leis gerais inscritas na natureza humana. Nisto se apóia a historiografia pragmática e o conceito de "lei histórica". Provavelmente pode-se extrair da história 'lições' e 'morais' No entanto, parece que se há 'recorrências', estas serăo sempre em outra situação a nível de época, e com outra constelação de circunstâncias, que fazem muito problemático falar-se de "leis históricas" propriamente ditas (não de leis econômicas e sociológicas que se cumprem na história). Quando não se chega até aí, considera-se a história como 'prosecução'. Isto pode ocorrer ou porque persista o pretérito ou porque o futuro unifique. $O$ pretérito pode persistir por inércia ("usos e costumes", instituiçôes), ou porque venha objetivado em monumentos, utensílios, linguagem, ou porque o agente humano conte com ele como experiência exemplar até o ponto de ter podido J. Ortega y Gasset (1883-1955) em 'História como sistema' defini-la como 'o sistema das experiências humanas que formam uma cadeia inexorável e única'. Por sua parte, o futuro atua como unificador dos agentes históricos enquanto 'mito atrativo', quer seja de restauração de um passado melhor ('idade de ouro', 'fervor primitivo' de qualquer ideologia), quer de criação de um 'futuro melhor' (Império ou Estado Universal, Era Feliz). Quando não se toma uma decisão sobre ser a história recorrência ou prosecução, mas se atende somente à gênesis dos fatos, temos simplesmente a historiografia genetista de Ranke (1795-1886).

Apesar de ser continuação, a história é também variação. Isto explica expressões tão correntes, também do século XVIII, como 'época', 'nível histórico', 'altura dos tempos'. De modo diverso ao intemporal ou ao que se considera 
repetível, a história aparece como seqüência irreversível criadora de novidade qualitativa e a diverso 'tempo' A esta ênfase da história como "escada", onde cada um de seus degraus pressupōe os passados e condiciona os vindouros, é a que se alude, de ordinário, quando se fala de "consciência histórica" e de "historicismo", como veremos mais adiante.

Mas já ficou dito antes que por historicidade também se designa aquilo que por essência, em caso de existir, deve existir transcorrendo em história. Socialidade, personalidade e culturalidade parecem ser as coordenadas que delimitam o histórico. Certamente o historiador só tem expressamente por tais a certos fatos e a certas entidades ou de grupos ou de forma. Mas se se exige maior radicalidade ao raciocínio, isto implica atribuir a historicidade ao homem enquanto indivíduo instalado socialmente. É o que desenvolveram com matizes vários, autores como J.M. Heidegger, (1889-1968) e J. Ortega y Gasset (1883-1955).

\section{A HISTÓRIA DO DIREITO: PROBLEMÁTICA E METODOLOGIA}

História do Direito é, segundo uma das acepções descritas, a ciência que se ocupa do Direito no passado. As consideraçōes feitas no apartado anterior aplicam-se quase como numa relação gênero-espécie para a história do Direito. Com efeito, a história do Direito é parte da história geral e no mais das vezes utiliza os mesmos métodos, fontes, etc. Há uma história universal do Direito e histórias do mesmo nos diferentes povos e épocas; uma história geral e uma história de seus diferentes ramos e especialidades.

De início, podemos asseverar que, cultivada em sua dupla finalidade, como parte da ciência histórica e como parte da jurídica, a história do Direito das Nações, diversamente da história do direito romano, viu acentuar nos diferentes países uns e outros caracteres. A continuidade ou ruptura com o próprio direito antigo determina seja seu estudo considerado como uma dimensão da ordem jurídica vigente ou como mera experiência histórica. Em um mesmo país, reforçase ou debilita-se o sentido da própria tradição jurídica, dependendo das épocas e dos autores. A concepção fundamental a respeito do Direito e acerca dos limites e possibilidades do conhecimento histórico determinam várias posições da história do Direito. Mas existe, sem dúvida, uma doutrina comum histórico-jurídica, cujas linhas fundamentais tentamos destacar.

A partir de Gustavo Hugo (1764-1844) admite-se uma distinção entre história externa e interna do Direito. A primeira compreende as fontes e notícias sobre sua origem, alteraçūes e destino; limita com a história política e com a história da ciência jurídica. A história interna refere-se aos conceitos e normas de Direito, a sua origem e modificações. Esta divisão foi objeto de diversas 
formulações e também de críticas, fundadas na unidade essencial do fenômeno histórico-jurídico. No entanto, as diversas tentativas de refundí-las ou mesclálas não afetam a efetividade da distinção original.

O objeto da história do Direito deve ser considerado de um ponto de vista histórico e de um ponto de vista jurídico-sistemático; o primeiro é dominante na história das fontes; o segundo, na história das instituiçōes. O sistema conforme o qual haja de organizar-se a história do Direito pode ser ou o adotado convencionalmente pelo historiador, ou o consistente em buscar para cada época a sua ordem peculiar de relações. A aplicação de conceitos e categorias jurídicas atuais a épocas nas que não foram conhecidas, dá lugar a deformações na imagem histórica, que se tenta corrigir mediante uma fidelidade estreita às próprias expressões dos textos jurídicos de cada época. A inclusão de acontecimentos históricos não jurídicos (políticos, econômicos, culturais) pode igualmente desvirtuar a índole específica da história do Direito; mas uma referência a eles será, às vezes, necessária para esclarecer o sentido próprio do acontecer jurídico. A atenção ao anti-jurídico de cada época está igualmente justificada. A delimitação nacional da história do Direito não apresentou dificuldades para a historiografia do século XIX, imbuída do dogma da escola histórica, segundo a qual há um espírito do povo que preside as diversas manifestações culturais de cada nação, e entre elas, o Direito. Quando uma nação apresentava zonas culturais diversas, tentou-se estabelecer este espírito por um processo de síntese, que muitas vezes consistia só numa confusão. A historiografia anterior ao século XIX revela o caráter regional da história do Direito, e igualmente deve assinalar-se para determinados momentos e aspectos do Ordenamento jurídico um caráter local definido. Tema habitual procedente de uma concepção científiconatural da história é o dos elementos formativos de um determinado Direito. Em geral, para as naçōes européias admite-se que estes elementos são fundamentalmente o elemento primitivo de cada país, o romano e o germânico; acrescente-se o canônico, e para a Península admite-se a particularidade dos elementos muçulmano e judeo.

O método da história do Direito funda-se no conhecimento crítico das fontes. A teoria geral das fontes históricas é remodelada para a história do Direito, pela significação que nela têm aquelas que devem ser consideradas como fontes do Direito de cada época, por contar suas leis, costumes, jurisprudência e doutrina, com a advertência de que a significação relativa destes termos é peculiar a cada época. No âmbito da vigência, as fontes são universais, nacionais, territoriais ou locais. Fonte indireta, por não conter a mesma norma jurídica, são os documentos de aplicação do Direito e as fórmulas ou modelos que servem para redatá-los. Às vezes, não revelam a aplicação, mas a criação do Direito. Há, na realidade, várias formulações do Direito: uma delas, a documental. Fontes indiretas da história do Direito são também as não-jurídicas, mas que transmitem notícias desta índole: fontes narrativas e literárias. Os problemas críticos das fontes, referem-se à determinação de sua natureza, autor e proce- 
dência, o tempo e lugar de sua formação, e a transmissão da mesma no curso da qual pode ser objeto de alteraçōes. A autenticidade das fontes que pode afetar cada um de tais aspectos adquire em história do Direito uma especial significação pela existência de falsificações mediante as quais se pretendeu apoiar determinadas pretensōes jurídicas. Do ponto de vista histórico, não se pode esquecer que a falsificação utiliza elementos ou modelos autênticos. Na interpretaçāo das fontes jurídicas entrem em jogo, ao lado de fatores puramente históricos que permitem identificar pessoas, lugares e acontecimentos, outros especificamente jurídicos que hão de ser preferentemente os relativos à ordem jurídica na que a fonte está situada, mas que deve também contar com a unidade da cultura jurídica.

O modo de exposição da história do Direito, objeto de várias tendências, obedece à finalidade perseguida; é fundamentalmente cronológico e sistemático. A periodização da história do Direito adota a clássica divisão em Idades Antiga, Média, Moderna e Contemporânea; ou ainda estabelece períodos derivados do acontecer histórico jurídico: a formação de grandes monumentos legais; as transformaçōes do Direito Público, como o território ou a forma de governo. Admite-se, em geral, que o ritmo histórico é diferente segundo os diversos ramos do Direito, e que estes são mais ou menos afetados pela mudança de condições econômicas, sociais ou espirituais da época. Tenta-se reconstruir a história do Direito como um acontecer especial, dotado de unidade, continuidade e sentido, e com um certo gênero de necessidade. Para esta concepção da história, de raiz idealista, os textos jurídicos são como que testemunhos que corroboram ou simbolizam este acontecer obediente a certas leis ou constantes. Mais antiga é a atitude do historiador que se dirige para os textos jurídicos como o objeto, e não como o meio, próprio e específico de sua investigação, e encontra neles os monumentos da cultura jurídica. Então, a crítica não trata já de verificar um testemunho, mas de caracterizar a sua índole, alcance, formação e conseqüências. No exame destes textos, obtêm um singular relevo as alterações sofridas pelos mesmos e as relações de procedência e derivação entre eles, que refletem a continuidade de uma tradição literária na que é de preferente interesse a identificação dos autores, individuais ou coletivos, assim como sua pertinência a determinadas escolas e âmbitos culturais, e a função profissional na que surge a obra, que é o ensino do Direito, a legislação, etc.

Ao tomar como objeto da história do Direito os livros jurídicos, a história externa dirige-se às circunstâncias de sua localização, transmissão e difusão. A história interna atem-se a dois aspectos:

1. À estrutura dos livros de Direito, que fundamentalmente adota duas formas:

a) a mera justaposição de elementos, tal como se foi produzindo a sua fi- 
xação por escrito: coleções de privilégios, leis, sentenças, e cuja ordem costuma ser cronológica;

b) a colocação de acordo com uma ordem sistemática que é peculiar de cada cultura jurídica ou procedente de outra.

2. Ao conteúdo destes livros (as figuras jurídicas em particular), cujo tratamento está determinado por:

a) uma tradição que as conserva e adapta a novas necessidades;

b) a criação de outras figuras novas para responder a necessidades surgidas nas diferentes esferas.

Caráter histórico do Direito é a sua contingência: realidades configuradas juridicamente em determinadas épocas históricas podem deixar de sê-lo e ficam submetidas a uma regulação moral, social ou arbitrária; por outro lado, outras épocas podem imprimir a forma do jurídico em realidades até então sujeitas a estes outros tipos de regulação. A própria ordem jurídica é contingente em sua totalidade: não necessária. Pode haver, e de fato houve, épocas, lugares e situações sem Direito. Este é o limite da história do Direito.

\section{HISTORICISMO JURÍDICO E HISTÓRIA DO DIREITO}

O termo "historicismo" ou "historismo" apresenta duas vertentes: uma negativa e outra positiva. Em sentido negativo denomina-se, com freqüência, pensador historicista ao que concede atenção exclusiva às realidades históricas e não admite como objetos válidos de conhecimento humano as realidades superhistóricas (verdades e normas imutáveis, transcendência, etc.), caindo, em geral, no erro relativista de pensar que tudo é mutável, e passageiro, como o tempo, e que o que hoje parece verdade, talvez amanhã não o seja. Positivamente o movimento historicista responde à capacidade de valorizar segundo $o$ justo as realidades que ostentam uma condição de irredutivelmente individual-comunitário-histórica, em virtude da qual não vêm dadas ao homem como objetos fixos, delimitados, antes devem autodesdobrar-se em ativa vinculação a seu entorno e conseguir assim a sua plena vinculação.

Estas duas vertentes - em aparência opostas - respondem ao fato de abordar uma tarefa filosófica muito complexa, a de fazer justiça a objetos de conhecimento que não se reduzam a meros objetos, com recursos metodológicos precários. O deslumbramento da "consciência histórica" teve lugar no século XIX sob o influxo por uma parte, da metafísica idealista, marcadamente especulativa e, por outra, da escola histórica (Droysen, Ranke) caracterizada pelo ater-se experimental ao que é dado. 
Certamente consagraram os historicistas de diversas tendências, notáveis energias à valoração das realidades ainda que não souberam harmonizar natureza e liberdade, e natureza e história; seus métodos, e a herança filosófica recebida eram só os da Ilustração e do idealismo, não chegando a conhecer as conquistas da filosofia clássica perene.

Embora o historicismo tenha a sua sede própria no campo estritamente filosófico, também tem profunda repercussão no campo do pensamento históricojurídico.

Como reação ao jusnaturalismo racionalista, principalmente de Ch. Wolff (1679-1754) e seus seguidores, surgiu em princípios do século XIX o movimento historicista, iniciado pela Escola histórica do Direito. Há que se ter em conta que grande parte das idéias que serviram de base ao primeiro historicismo jurídico já tinham sido sugeridas por alguns autores do século XVIII. Em 1725 publicava Vico os "Princípios de uma ciência nova em torno da natureza comum das nações, pela qual se descobrem outros princípios de Direito natural das gentes". Pouco tempo depois, C.L. Montesquieu (1689-1755) dedicava grande parte de sua obra "L'esprit des lois" (1748) a descobrir uma série de elementos condicionantes da variedade histórica e geográfica do jurídico legal, como são a situação de cada país, seu clima, sua qualidade de território, extensão, gênero da vida de seus habitantes, a religião que professam, a densidade demográfica, as relações comerciais e econômicas, assim como seus costumes e usos próprios. Outro dos indiscutíveis propulsores do movimento historicista foi J.G. Herder (1744-1803) que, ao estudar as origens da linguagem, descobre a idéia-chave do primeiro historicismo jurídico, a saber, a idéia do povo (Volksidee) como entidade nacional e racial com a sua própria individualidade cultural.

O predecessor imediato da Escola histórica do Direito foi, no entanto, o já citado G. Hugo, cujas diretrizes doutrinais foram muito bem aproveitadas por F.K. Savigny (1779-1869) ao traçar o programa da Escola histórica do Direito. Frente a todas as Escolas anteriores, qualificadas por Savigny de 'ahistóricas', o objetivo fundamental da Escola histórica do Direito era demonstrar que o Direito procede radicalmente do modo de ser 'natural' de cada povo, sendo este concebido como nação autônoma, de tal modo que existe uma coerência orgânica entre a essência e o caráter de cada povo e seu Direito. Da mesma forma que o idioma, o Direito se acomoda ao longo de sua evolução histórica ao desenvolvimento progressivo de cada povo. O programa de Savigny foi continuado principalmente por Puchta, que lhe deu maior unidade sistemática, concebendo o Direito como uma convicção comum de quem vive em uma comunidade jurídica.

Da Escola histórica do Direito, surgiu como derivação mais importante a Escola etnológica, dedicada a explorar o direito dos povos primitivos, dando 
assim origem à Etnologia jurídica. Pouco depois surgiu a Ciência do Direito comparado, cuja finalidade principal era descobrir, agrupar e descrever os elementos comuns a todos os direitos históricos. Por este caminho, houve os que chegaram a assinalar a existência de forças polares de sinal contrário na evolução histórica do Direito. Com maior segurança, no mundo anglo-saxão, $\mathrm{H}$. Summer Maine (1822-1888) chegou à conclusão de que todos os sistemas jurídicos historicamente existentes procedem de dois tipos de sociedades: um estático, que se rege pelo 'status', e outro dinâmico, regido pelo 'contractus'. Em todos eles, no entanto, produziu-se uma evolução 'From status to contract'. Unindo a tese básica da Escola histórica do Direito com os princípios do positivismo, apareceu em finais do século XIX o que podemos chamar de positivismo jurídico historicista, cujos postulados fundamentais persistem ainda em parte no pensamento jurídico do século XX.

Ainda que não exista nenhuma relação de dependência estrita entre Hegel (1770-1831) e a Escola histórica, o certo é que dele procede a conhecida expressão espírito do povo (Volksgeist), que depois é utilizada também por Savigny em seus 'Sistema de Direito romano atual' (1840). Para Hegel, somente o que ele chama Direito abstrato ou formal, baseado na idéia de liberdade, está por cima da temporalidade histórica; mas este Direito só contém proibições jurídicas (Rechtsverbote). O que chama Direito natural ou filosófico, o mesmo que o Direito positivo, que é o único Direito válido, baseia-se na idéia de comunidade e na moralidade objetiva. A comunidade é primariamente o povo como parte do Espírito absoluto, que se desenvolve a si mesmo através de três momentos dialéticos: tese, antítese, e síntese. Tanto o Direito natural, como o Direito positivo são, portanto, Direitos históricos, sendo a relação entre eles similar à que existe entre as Instituições e as Pandectas. Ademais disto, Hegel afirma que existe uma identidade radical entre o real e o racional, conforme o princípio "o que é real é racional e o que é racional é real"

O historicismo objetivo-idealista de Hegel converte-se com Marx em historicismo econômico-materialista. Marx imputa a Hegel o esquecer-se do homem real que come e bebe, necessita vestir-se e ter onde morar. Para Marx a única realidade histórica é a vida material do homem. Este deve converter-se em força produtiva para poder sobreviver. Não há oposição entre natureza e história, pois tanto uma como outra dependem da vida material do homem e crescem ao ritmo da estrutura econômica e do desenvolvimento econômico. Se o Direito se separa da estrutura econômica, converte-se em uma de tantas ideologias, é uma superestrutura. Propriamente, o Direito há de ser uma conseqüência das relações econômicas, entendidas em sentido histórico-materialista, transformando-se em um instrumento a mais para a implantação da sociedade comunista futura. Esta interpretação errônea e funesta do Direito é seguida pelo marxismo posterior, acomodando-a, inclusive, às vezes, à situação política, como acontece com a versão leninista ou stalinista e nos neomarxistas contemporâneos. 
Por último, cabe destacar o historicismo vitalista, de perfil preferentemente gnoseológico, cujo principal iniciador foi W. Dilthey (1833-1911), para quem o Direito pertence à categoria das "ciências do espírito", cujo objeto e método é diferente o objeto e mẹ́todo das "ciências da natureza". Estas últimas baseiam-se no conceito de causa e seu método de conhecimento consiste em descobrir um sistema de relaçōes causais; já as ciências do espírito, também chamadas culturais ou históricas, têm por objeto as realidades do chamado mundo humano, sendo o seu método de conhecimento a compreensão de tais realidades utilizando as categorias conceituais de fim, sentido e valor. Dentro destas categorias, ocupa um lugar de preferência o Direito, que, por sua referência a um fim, está em relação direta com os sistemas de cultura, variando histórica e sociologicamente como estes.

\section{BIBLIOGRAFIA}

ACUÑA, Fernando F., História del Derecho, San José (Costa Rica), 1972.

BALIÑAS, C.A., El acontecer histórico, Madrid, 1965.

BRAGA DA CRUZ, G., História do Direito Português, Coimbra, 1953.

CAETANO, M., Lições de História do Direito Português, Coimbra, 1962.

GILBERT, R., Historia General del Derecho español, Granada, 1968.

MILLAN PUELLES, A., Ontologia de la existencia historica, Madrid, 1955.

MOLINERO, M.R., Historicismo: Filosofia del Derecho, in Gran Encilopedia Rialp, vol. XII, Madrid, 1973.

MUNILLA, O.G., Historia: Concepto y Ciencia, in Gran Enciclopedia Rialp, vol. XII, Madrid, 1973.

RAO, Vicente, O Direito e a vida dos Direitos, São Paulo, 1955.

WIDGERY, A.G., Les grandes doctrines de l'Histoire, Paris, 1965. 